Title:

\title{
Towards a Taxonomy for Regulatory Issues in a Digital Business Ecosystem in the $\mathbf{E U}$
}

\author{
Authors: \\ *Panayiota Tsatsou, PhD (First author) \\ Silvia Elaluf-Calderwood, $\mathrm{PhD}$ (Second author) \\ Jonathan Liebenau, PhD (Third author) \\ *Swansea University \\ Singleton Park \\ Swansea SA2 8PP \\ Wales, UK \\ \{p.tsatsou@swansea.ac.uk\} \\ $\&$ \\ London School of Economics and Political Science (LSE) \\ Houghton Street \\ London WC2A 2AE \\ England, UK \\ \{s.m.elaluf-calderwood,j.m.liebenau@1se.ac.uk\}
}

\section{Acknowledgements}

The authors wish to thanks the Media Lab at the Department of Media and Communications and the Information Systems and Innovation Group, both at the London School of Economics for their support in the research work completed by the authors within the framework of the Digital Business Ecosystem (DBE) Project in FP-6 EU, project task WP32-B11.

The authors are particularly grateful to Paolo Dini, Gordon Gow and Robin Mansell for their continuous support and guidance over the course of the research. 
Title: Towards a Taxonomy for Regulation in the EU Digital Business Ecosystem

\section{ABSTRACT}

This paper addresses the role of trust and regulation where small and medium-sized enterprises (SMEs) in the European Union make use of e-business in a digital business ecosystem (DBE). We argue that in order for digital business to develop among entrepreneurs in the EU and within different industry sectors and geographical locations, trust and regulation are of critical importance. The paper assesses the importance of this argument and focuses on the interplay of regulatory and trust-based issues that need to be accommodated before one can expect SMEs to engage in ebusiness supported within a DBE environment. It then presents a taxonomy that addresses key regulatory issues and fosters trust. The paper proposes the taxonomy as the vehicle for the simplification of a bewildering array of laws, standards, norms and expectations, as well as for the elimination of regulatory overlap and conflict. The contribution of the taxonomy is demonstrated in the last section of the paper, where it is empirically tested and applied to SMEs which participated in the EU funded DBE project.

KEYWORDS: Digital Business Ecosystem (DBE), trust, regulation, taxonomy, SMEs

\section{INTRODUCTION: TRUST, REGULATION AND TAXONOMY FOR A DIGITAL BUSINESS ECOSYSTEM IN THE EU}

Policy makers in the Commission of the European Union have identified the adoption of new forms of e-commerce and e-business in small and medium sized enterprises (SMEs) as a key 
priority for fostering innovation and the competitiveness of European SMEs in global markets (EU Commission, 2005). Since the early phases of online commerce the notion of trust has been brought to the fore as a key enabler of such an activity, being mainly related to security and privacy for commercial websites (Berkey, 2002; Black 2002).

Trust relationships are central to e-business activities not only because any kind of economic transaction requires a level of confidence, but also because trust is usually cheaper to establish than contracts, and since contracts cannot specify everything necessary, trust fills in where they fall short. The evolution of the notion of trust has taken on additional and pervasive attributes and some see it as the foundation of the digital economy (Shankar et al. 2002; Pavlou 2002) - an economy that involves new organisational forms, collaborative activities and extended partnerships that rely on trust relationships for their success.

Mechanisms for minimising risk and establishing trust have existed for a long time, with regulatory mechanisms being of critical importance. However, regulations applicable to e-commerce and ebusiness transactions are marked by incompleteness and inconsistency, which imposes a certain degree of fluidity and uncertainty (Hornle, 1999; Splinder et all, 2004). The literature on e-business participation among SMEs demonstrates the lack of knowledge and resources to address this regulatory confusion as one further barrier to the development of e-business among SMEs (Mahler, 2004; Shelbourne et all, 2003). In the European case, this regulatory difficulty is expressed by the differences between legislation on national levels and the recent implementation of EU Directives relating to e-commerce. The EU member countries, plus accession candidates and others who wish to be compliant, and the 20 languages used to distribute guidelines about e-businesses practices also contribute to the slow adoption of e-business in Europe (EbusinessLex, 2005). 
In this paper we examine the importance of trust and regulation for SMEs in the EU that are participating in the digital business ecosystem (DBE). Following from this examination, we are able to propose a taxonomy that serves as the framework for a knowledge base of regulatory issues, leading to enhancing trust relationships in the DBE. The DBE concept as well as the arguments that this paper makes reflect on the work carried out in the European Commission's $6^{\text {th }}$ Framework Digital Business Ecosystem (DBE) Project ${ }^{\mathrm{i}}$. The paper reports specifically on part of the work carried out in the regulatory framework [Task B11 - WP32] part of the DBE project. This was work that involved the design, implementation and description of a sector-specific and localised knowledge base of e-regulatory issues which was intended to be compatible with the vision of the DBE to provide an open, free environment where even the smallest specialist software developer can participate competitively in the massive global marketplace for business applications.

In general, the DBE aims to enable SMEs in different localities and industry sectors in Europe to access and use easily those applications as services, so that they have the benefits of intelligence, interaction and adaptation as the software evolves in response to their own usage and that of others (see: http://www.digital-ecosystem.org/). As envisaged by Nachira (2002: 18), the DBE is intended "to create an integrated, distributed pervasive network of local digital ecosystems for small business organizations and for local e-governance which cooperate [when] exchanging dynamically resources, applications, services and knowledge".

With regard to trust and regulation issues, the DBE aims to stress the importance of regulatory issues in digital business among SMEs in Europe and the significance of establishing trust relations that enable regulatory stability. This aim was pursued through the development of a knowledge 
base of regulatory issues ${ }^{\mathrm{ii}}$ that facilitates the establishment of trust in key areas of regulatory interest. The requirement to create a knowledge base is, however, an "evolutionary systemic process" (ibid: 13) that accommodates the range and intricacy of norms and laws that apply to any number of business organisations operating in different sectors and across various jurisdictional domains. It also addresses the immense challenges associated with organisational and cultural differences that affect the activities of SMEs (Burn 2000; Hornby et al., 2004). This is especially so given that SMEs tend to avoid legal risks such as those encountered in cross-border commerce (Nachira 2002:6). Our purpose here is to establish a knowledge base of regulatory issues, preparing the ground for the further elaboration of regulatory architecture and governance models in the field.

In what follows, the concept of trust and its facets in e-business are discussed. In the second section, the paper presents three salient blocks of regulatory issues. The outcome of the review takes shape, in the third section, in the proposed taxonomy intended to identify, classify and assess regulatory issues relevant to the DBE vision. The taxonomy constitutes a framework that provides a presentation of key regulatory issues and of their correlations to increase awareness among involved parties and to develop a generic knowledge ${ }^{\mathrm{iii}}$ basis of regulatory issues. This taxonomy is subjected to empirical testing and enrichment, and a synopsis of the empirical findings obtained is briefly provided in the last section of the paper. We conclude by underlining the contribution that the taxonomy can make and the foundations it provides for further research in sector specific and local implementation cases among European SMEs.

\section{TRUST AND REGULATION: THE DBE CASE}

In working to identify and assess the DBE regulatory domain, the paper adopts the thematic notion 
of trust as the initial point of focus. Both academic commentators and practitioners increasingly recognise trust as a critical enabler of e-business (Yovovich 1996; Sultan et al 2002; Swan \& Rosenbaum 2004; Ruppel et al 2003; Keen 2000; Clarke 2002a). Trust, therefore, provides the thematic backdrop to the key question that guides the overall discussion in the paper:

Which are the key regulatory issues that have been identified as the most significant for the initial adoption of e-business services among European SMEs and for building and maintaining trust in the DBE?

The DBE is ambitious and clearly seeks to move beyond "e-business" and toward a vision portrayed by Nachira (2002) as a ladder of adoption for internet technologies. This ladder of adoption suggests, at least methodologically, that certain fundamental trust and regulatory concerns affecting the implementation of the DBE must be addressed early on in the process. Let us consider the three trust facets proposed by Nachira (ibid).

\section{$\underline{\text { Trust facets }}$}

A trust relationship can be described as:

The willingness of a party to be vulnerable to the actions of another party based on the expectations that the other party will perform a particular action important to the trustee, irrespective of the ability to monitor or control that other party (Mayer, Davis and Schoorman 1995)

Trust relationships enable action by establishing confidence among interested parties in the expected outcomes of current or future transactions (Clarke 2002a; Dutton and Sheppard 2004). In the context of online commerce, however, trust relationships may be more difficult to establish and sustain. Not only are there challenges in establishing the trustworthiness of parties in an online environment but electronic networks also provide increased possibilities for egocentric and untrustworthy behaviour compared to other settings (Mansell and Collins 2004; Pavlou 2002; 
Jarvenpaa and Tractinsky 1999, Clarke 2002b). Recent research on barriers to e-business indicates that the difficulty in establishing trust relationships has been the main deterrent for companies globally to engage in e-business activities (Shankar et al. 2002), and within the EU context (EbusinessWatch 2004) in particular.

Regulation can be central to building trust relationships, as it could provide confidence to engage in economic exchange. However, the identification of specific trust facets for e-business activities comes to the fore as the first prerequisite for SMEs operating in a complex regulatory environment, while constituting the ground on which key domains of trust regulation are identified. The following facets of trust proposed by Nachira (2002: 14) are thus briefly reviewed:

\section{a. Trust in services and in technological solutions}

This form of trust is a measure of confidence expressed in terms of security and reliability. This facet comes close to the notion of 'technological trust' (Rosenbaum 2004) or 'belief that technologies will perform reliably and will not be used for untoward purposes'. For trust relationships to develop within the DBE, developers and users need to have confidence that both the basic layer and supported applications provide a necessary degree of security and that risks to the services provided using the DBE platform are minimised.

\section{b. Trust in business activities}

Trust in business activities is a measure of confidence expressed in terms of mutual recognition of accepted practices and procedures for specific sectors and local contexts. This facet of trust is related to the notion of 'institutional trust' or a collective expectation that the procedures needed for carrying out transactions successfully will be facilitated and followed (Pavlou 2002). For companies to successfully adopt and continue using DBE services, there will need to be trust relationships established in regard to the expected patterns of behaviour and organisational 
practices adhered to within the environment - without that cultural and organisational differences are likely to inhibit the formation of business relationships in the DBE.

The DBE does not provide a fixed scope of e-services. Rather, it provides a platform through which participating firms can provide services. Typically these are computer services provided to clients on the DBE platform. Therefore, in order for trust to exist in the business activities taking place via the platform, it is important to know if the clients have any computer knowledge or not; if they have a computer department or not and the extent of those resources. Opportunities as well as liabilities depend on these resources and the opportunity to establish trust in business activities can thus become more or less feasible, if not certain.

\section{c. Trust in Knowledge}

Trust in knowledge is a measure of confidence expressed in terms of symmetric access to information. Because knowledge is a critical asset in e-business activities, differences in access to information relevant to e-business activities can lead to unequal advantage within the business ecosystem environment. Hence facilitation of symmetric knowledge sharing and equal access to information is important for establishing trust relationships between companies participating in the DBE.

Addressing each of these facets of trust in the DBE depends on a variety of factors, including organisational arrangements, technological solutions, cultural norms, economic and competition considerations, and crucially, the regulatory and legal environment within which the ecosystem will operate. Thus the discussion that follows turns to the examination of the role of regulatory challenges in establishing and sustaining trust relationships between e-business parties, concluding with a proposal for approaching regulatory trust in the DBE environment. 


\section{$\underline{\text { Categorization of regulatory issues }}$}

In the first phase of the DBE project, the researchers conducted a survey of regulatory issues, with the main categories being summarized in Annex 1 (Figure IV). However, a more focused approach was taken at a later stage, with specific blocks of regulatory issues addressed towards a taxonomy of regulatory issues for SMEs in digital ecosystems.

Of interest are the categories of regulatory issues suggested by Berkey (2002). In his review of literature from US, EU, and international organisations, Berkey refers to three categories of international regulatory issues related to e-business, which we regard as building blocks of regulatory trust. Each of these building blocks provides the foundation for developing a more complex investigation and analysis of regulatory issues relevant to sector-specific and local implementation of trust relationships in the DBE.

The aim of these blocks of regulatory issues is to establish the initial research paths leading to a self-sustained regulatory model for digital business ecosystems. However, as primary blocks they are not exclusive. Further relevant categories of regulatory issues could be added, as DBE enterprises develop complex relationships and other economic and social parameters could be of importance for the sustainability, governance and legal identity of the DBE. Nevertheless, the three blocks of regulatory issues are described in more detail as follows:

\section{a. Privacy and consumer protection}

Privacy refers to the non-disclosure of stored or transmitted information relating to a uniquely identifiable entity, while data protection is the prevention of unauthorized access to this information. This issue is closely linked to consumer rights and existing legislation comprehensively covers $\mathrm{B} 2 \mathrm{C}$ transactions, while for $\mathrm{B} 2 \mathrm{~B}$ contracts the rules are less stringent. Due 
to a lack of international consensus and coherent regulatory approach to privacy and data protection issues, differences between the rules applicable in non-EU countries and among the EU states are likely to create obstacles for companies seeking to adopt e-business practices.

In the context of digital business ecosystems, issues related to the management of databases shared between members of the ecosystem are critical, as these databases are likely to contain information to which privacy controls are applicable as well as to create sensitive commercial data patterns. Other concerns include relevance and proportionality in the access to the database and accuracy in the use of data, an evaluation of data sensitivity, and, finally, a need for a policy on the rights of companies to prevent or allow transfer of sensitive data.

In this area, three are the key challenges to be encountered:

- To define the level of data sharing that does not violate data protection regulations;

- To establish terms and conditions between partners to ensure that data will not be shared with third parties external to agreements;

- To establish a means of generating traceable records to deal with any breaches of the data sharing agreements.

\section{b. E-signatures and Authentication}

The building block of e-signatures and authentication is closely related to security issues in ebusiness. While in many cases these issues are of a technical nature, regulatory considerations are particularly important in the areas of authentication, digital signatures, electronic invoicing and payments. Concerns related to this building block are crucial for trust relationships in e-business, since authentication supports both access and denial of access to different resources, determining 
the means for identifying malpractice and providing an audit trail of transactions necessary for resolving disputes.

EU level legislation provides a basic framework for the use of electronic signatures for authentication; however, the process and the bodies responsible for certification are decided by each member state. Current regulations also address issues related to encryption, electronic storage and the use of e-payments and e-invoices. In the digital business ecosystem vision, relationships between participants will lead to payments or transactions of some type, and the issues related to esignatures and authentication will be important for establishing and sustaining trust between partners. In addition, considerations of interoperability of electronic invoicing systems and the traceability of processes within these systems may be significant factors in ensuring successful collaboration among partners.

\section{c. Jurisdiction and Consumer Protection}

The building block of jurisdiction and consumer protection refers to the broad category of regulatory issues stemming from the cross-border nature of e-business transactions. From the perspective of the e-business ecosystem, the main concerns in this building block centre on regulatory issues related to cross-border online contracting.

The validity of electronically concluded contracts may be a concern for two reasons. First, while there is an EU Directive requiring non-discrimination between on- and off-line contracts, it has not yet been implemented uniformly by all member states and electronic forms may not be valid in some cases due to specific sector or local requirements. Second, while the B2C online contracting process is covered by existing legislation, difficulties with determining legal validity or the binding power of a contract may arise in B2B transactions, as it is determined based on the contract law of 
the governing jurisdiction. This may turn out to be a barrier to successful electronic contracting between SMEs joining the ecosystem.

Issues related to jurisdiction are crucial in a cross-border e-business setting: not only do approaches to determining the governing jurisdiction vary between countries but also there are significant differences in regulations applicable to e-business in different jurisdictions. This may create risks for SMEs when jurisdiction is not agreed prior to contract, and there are further uncertainties caused by the fact that jurisdiction is not always easy to determine in e-business settings. SMEs joining the digital business ecosystem environment may need information on the rules for determining jurisdiction and requirements applicable to e-business in other jurisdictions. It may also be necessary to accommodate the negotiation of jurisdiction prior to the conclusion of the contract in the DBE contracts framework.

Requirements of information provision related to the contract (provider details and contracting process) set out in the EU regulatory framework are currently a challenge for SMEs. First, there is little awareness of these requirements, leading to non-compliance on the SME side, and second, insufficient information provision to potential customers is often a reason for lack of trust towards the provider. Challenges related to potential product and service liabilities and resolving crossborder disputes may be particularly relevant for the SMEs who have little resources to spare for costly and lengthy processes involved. This issue is a major barrier to e-business uptake by the SMEs, who may abstain from e-business activities associated with the risk of litigation in different countries under inconsistent laws. Online dispute resolution (ODR) mechanisms, which represent an alternative to litigation in court that is cost-efficient and time saving, may be particularly suited for the SMEs. However, most of the ODR schemes so far have been designed for C2C or B2C disputes and it is yet unclear how well these are suited in a B2B environment. It may be important 
to consider alternative ways of resolving disputes through ODR mechanisms and, in the long run, to look for possibilities of establishing such schemes within the digital business ecosystem to ensure efficient and fast resolution of disputes.

These categories of regulatory issues are proposed as the building blocks of regulatory trust in the DBE, meaning that they are priority concerns when developing e-business initiatives in context. However, these are generic layer building blocks, tending to identify a broad set of concerns without specifying how those concerns are relevant to any specific set of local or sector-specific circumstances. It is thus necessary, from a methodological standpoint, to first establish these generic layer building blocks and to then move towards higher order specifications in sector and local implementations (see Figure I).

\section{TAXONOMY OF REGULATORY ISSUES IN THE DBE}

The need for an accelerated development of a coherent regulatory agenda in order to maximise the benefits of 'information society technologies' was first spelled out in the 1994 Bangemann report (Bangemann 1994). A further call for establishing a coherent legal and regulatory environment to enable 'vigorous growth in e-commerce' was raised by the 1998 Committee communication (European Parliament 1998).

However, as reflected by the Legal Barriers in e-Business (EU Commission 2004) consultation results, there are a number of obstacles that hamper the effectiveness of regulatory measures in online spaces and with regard to e-business in particular. Since the transposition of the EU directives to national regulatory frameworks has neither been uniform nor quick, the differences in 
legislation applicable at the national level increase legal uncertainty and raise the cost of regulatory compliance. Moreover, there are still major knowledge gaps and barriers caused by the complexity of the regulatory framework that need to be addressed in order for companies to be able to enter and operate in the e-business environment. All of these problems apply to a greater or lesser extent to all of the regulatory issues reviewed in the previous section of the paper and with regard to the SMEs participating in the DBE as well.

\section{Why a taxonomy?}

Here we propose a taxonomy of regulatory issues that identifies and classifies regulatory issues of relevance to the DBE. ${ }^{\text {iv }}$ It sets out boundaries and demonstrates the position of key regulatory features. It thus serves as a tool for directing the research on e-business ecosystem regulations in the future, while providing baseline knowledge and a common point of reference in order for regulatory and governance action to be taken. In this sense, the taxonomy contributes by guiding 'further discussions and the distillation of findings and existing knowledge' (Schoubroeck et al 2001b).

Overall, we argue that the taxonomy can increase awareness and constitute the ground for the establishment of a knowledge base of regulatory issues on the benefit of all involved parties, while stimulating empirical research, as shown in the last section of the paper and through the taxonomy's empirical application and testing. However, its contribution with regard to the establishment of a knowledge base of regulatory issues and to awareness raising should not be exaggerated, as the taxonomy will be a 'living organism' that evolves and changes over time on the ground of systemic and context-specific conditions of development. 
The following sections set out the taxonomy developed for classifying and analysing the regulatory issues of relevance to the DBE, on the ground of the constitutive elements of trust types and regulatory building blocks discussed in the previous sections, as well as of the operational perspectives introduced in what follows.

\section{Trust types, regulatory building blocks and DBE operational perspectives in a}

\section{taxonomy}

The first classification adopted for the taxonomy is based on the notion of trust as a critical enabler of e-business activities in general and as the starting point for approaching regulation in the DBE context in particular. Three main types of regulatory trust in a digital business ecosystem environment were identified based on the model of trust suggested by Meents, Tan and Verhagen (2003) and developed for B2B virtual marketplaces (See Table I). First, participants joining a virtual marketplace must have confidence that it will provide secure services over proven technology, and that it is capable of facilitating trust relationships in business activities. This is referred to as Trust X. Second, there must be a level of confidence that other participants joining a virtual marketplace are not behaving opportunistically, perhaps through asymmetrical access to information. This suggests a need to ensure that opportunistically behaving companies are denied access or, alternatively, that symmetric access to information in certain areas is given high priority in order to deter unwanted opportunistic behaviours. This dimension is referred to as Trust Y. Finally, a virtual marketplace must ensure that trust relationships can be established between participants themselves; that is, it must engender confidence that bi-lateral transactions will be honoured. This dimension is referred to as Trust $Z$.

The second dimension of the taxonomy is constituted of regulatory issues that have been adopted on the basis of trust facets and types of transactions: as explained in the trust facets section of the 
paper, trust in services and in technological solutions, trust in business activities and trust in knowledge are of critical importance depending on business interactions and the distinction between $\mathrm{B} 2 \mathrm{~B}$ and $\mathrm{B} 2 \mathrm{C}$ transactions. Thus the building blocks of regulatory issues adopted for the taxonomy are those described in the categorisation of regulatory issues section of this paper as privacy and consumer protection, e-signatures and security, jurisdiction and consumer protection, and they are examined at three levels: generic, local-specific and sector-setting (Figure I).

Finally, the taxonomy has a third dimension, operational perspectives, introduced on the ground of the perception of taxonomy as a modality of analysis. As Schoubroek et al. (2001b) argue, the approach based on angles is useful because angles '...provide a better insight into certain [regulatory] issues, for example to whom they are important and at what time during the lifecycle they become crucial'. Therefore, we have accommodated the classification of operational perspectives according to the types of DBE actors, DBE relationships and the models of software development lifecycle that are potentially used in the ecosystem (see Table II).

Hence, the taxonomy proposed here can be portrayed as a three-dimensional matrix, with trust types, building blocks of regulatory issues and operational perspectives being part of the framework presented in Figure II. The taxonomy presented in Figure II links together these classifications and the particular operational perspectives in the DBE. Thus, any regulatory issue identified in further stages of research and analysis can be placed along the dimensions of the framework and examined for its relevance in any of the elements of the classifications adopted. Using this taxonomy, it is thus possible to narrow down the area to which specific regulatory issues belong and in which they are most relevant in order for further analysis to be carried out. However, in order for the validity of the taxonomy to be illustrated, we demonstrate empirically how to apply and verify the taxonomy through reflecting on SMEs' views. 


\section{TAXONOMY: EMPIRICAL APPLICATION}

This section presents the empirical application of the taxonomy, by reporting on some of the findings obtained from interviewing SMEs in different regions and industry sectors in the EU. At this point, the aim is to provide some useful methodological insights into how to test the taxonomy framework empirically and how this can feed future research in this area.

\section{Preliminary Survey of Regulatory Issues}

As implied earlier, the categories of regulatory issues included in the taxonomy were selected after conducting a survey of regulatory issues in the literature. The survey findings and the categorizations used to narrow their regulatory components (Annex 1, Figure IV) also constituted a significant tool in order the researchers to contextualise the taxonomy and to test it empirically through a systematic research process.

\section{$\underline{\text { Research design }}$}

At the outset of the empirical research, initial discussions with DBE project partners took place in order to understand possible usage scenarios for applying empirically the taxonomy. Furthermore, systematic network building with SMEs was employed to establish a reliable profiling of SME candidates to research. As a result of this preliminary work, a clearer picture of a number of considerations was formed to assist in the research design. 


\section{Definition of the scope of fieldwork}

Regarding the reach of the fieldwork, the scope of this empirical approach was defined according to the following criteria:

- Regulatory focus

- Focus on the basis of the three building blocks of the taxonomy.

- Open approach: use of the existing building blocks as support, but not as strict thematic boundaries, so that, when new areas arise, these can be taken into consideration for enrichment of the current taxonomy.

- Industry/Sector

- Three regions were selected: West Midlands in the UK, Tampere in Finland and Aragon in Spain, all of which joined the DBE at an early stage. Focusing on one region only would run the risk of not representing the DBE as a whole. As the main aim of the work was to develop a methodology for populating the taxonomy, it was helpful to research several different locations.

- A variety of sectors constituted the focus of the fieldwork. The selected regions exhibit a diverse range of industry sectors. In the West Midlands, e-commerce, content management and accountancy comprise the central business activities of the SMEs. In Finland, the SMEs act in developing Open Source software, whilst in Spain the SMEs develop travel agency software, tourist management software and consultancy in e-commerce.

- How many cases?

- Seven SME Drivers were selected for in-depth interviewing. Although this number cannot be considered to be large enough to represent the community of SMEs in Europe, it constitutes a 
diverse enough range of businesses that formed the regional communities in the DBE project and had an explicit interest in making use of the DBE platform (detailed information on the background of each SME Driver is provided in Annex 3).

\section{- DBE Actors}

- SME drivers and not SME users or regional catalysts were interviewed. SME drivers are SMEs who have the knowledge and expertise to manage technology in the DBE from the early or intermediate stage of its development, and they can be distinguished from SME users who can only apply this technology when ready for use. In this sense, drivers were more 'mature' and engaged with the DBE platform than simple SME users at the point when the interviews were conducted. Also, they were the first actors in the project getting updated and thorough information about research progress and advancement and those who first tested new features of the ecosystemic environment and platform. On the other hand, regional catalysts would provide a top-down approach to the issues at stake, failing to inform the study with the necessary insider's points of view.

- Selection of empirical cases

- Discussions with SME drivers candidates were held in order to identify their potential for participation. Then, the criteria for the final selection of SME drivers were defined, as shown in Figure III. According to Figure III, sector-specific and local implementation criteria defined the overall scope of the fieldwork, determining, in turn, the identification of seven cases in the regions of West Midlands (UK), Finland and Aragon (Spain), and in four key business domains: information systems integration (Finland), e-commerce and accountancy (West Midlands), as well as management software and e-commerce consultancy in tourist sector (Aragon). The selection of these cases for research relied also on considerations concerning their relevance to the theoretical and taxonomy framework as well as practical 
obstacles, such as timelines, SME drivers' willingness to be interviewed, travel and human resources, etc.

\section{$\underline{\text { Research methodology }}$}

\section{Interviewing: data collection method}

Interviewing was employed as the data collection method, as it was considered functionally compatible with the objectives of the research. Also, interviews provide the necessary freedom for eliciting new themes of regulatory concern and more implicit issues of regulatory relevance, both testing the taxonomy and allowing the emergence of new issues of regulatory interest. The usage of a fully structured survey questionnaire was not appropriate, as the goal of the research was not a strictly quantitative approach to SMEs' regulatory concerns about participating in the DBE. Also, surveys are not suitable for such small-scale empirical research and for the investigation of research subjects with different business interests at stake.

Hence, seven face-to-face, in-depth individual interviews were conducted with SME drivers in the three regions. The DBE researchers traveled to those regions, so as to obtain an insider's account of how business is done and what challenges to digital ecosystem research might be in place. All seven interviews were digitally recorded and were thematically analysed.

\section{Interview rationale and topic guide}

The goal of the interviews was not to propose any solutions to the regulatory issues raised by the SME Drivers or to expose the potential of the DBE to address these issues effectively. The aim was to approach regulatory issues according to theory (three building blocks of regulatory issues) and the taxonomy (the matrix of building blocks, trust types and operational perspectives), leaving space for reflections on current practices in sector-specific and local implementation business cases. 
A single interview topic guide was used in all seven interviews. Nevertheless, a degree of openness was ensured, as interviewees in different sectors come across different issues and concerns. For instance, a driver in the West Midlands acting in the area of e-commerce is more likely than an integration and software development company in Finland to come across issues of privacy and consumer protection. Therefore, the treatment of different drivers had to be mindful and the interview topic guide was to reflect sufficiently the varying areas of regulatory concerns.

In what follows, a brief outline of the interview guide is presented ${ }^{\mathrm{v}}$, while more or less minor variations were committed with regards to the characteristics and particularities of each SME driver:

- Background questions in terms of company profile and current business activities.

- Main regulatory concerns and legal issues, as these are raised by theory and were reflected by the drivers in all three regions.

- Regulatory concerns and further legal issues raised by current business practices of the drivers from a business domain and local perspective.

- Underlying factors influencing drivers' concerns, with the emphasis placed on the business domain and locality of each driver.

- Finally, challenges for the DBE and potential future prospects of the DBE environment.

In what follows, we present a more analytical approach to the reflections from the drivers in all three regions, thereby bringing to the fore the sector-specific and local implementation of the taxonomy and the potential implications for the future. 


\section{Empirical findings: DBE taxonomy validated and enriched. Implications for trust}

\section{and regulation issues for SMEs in the EU}

In this section we only refer to some of the empirical findings obtained, so as to give an indication of the potential of taxonomy to reflect SME's views and concerns and of how it can apply in practice. Although we could expand and report on empirical findings in relation to the whole range of regulatory issues initially surveyed in the literature (Annex 1, Figure IV), the work aimed to obtain empirical insights into the taxonomy and its validity only. In this sense, the general survey of regulatory issues rather operated as a point of reference that allowed taxonomy to be contextualised in broader areas of regulatory matters.

\section{Empirical reflections on regulatory issues from the DBE actor operational perspective}

The links established between the DBE and SME drivers in the UK (West Midlands), in Spain (Aragon) and in Finland provided invaluable feedback on issues related to the taxonomy. The SME drivers in the three regions covered different sectors of e-business (tourism, middleware, insurance, customized solutions) and in the interviews they reflected upon their individual roles as members of a digital business ecosystem, DBE actors, and with regard to the taxonomy presented above.

\section{SME Service Providers}

In general, SME drivers that perceive their role as a service provider underlined the problem of different national regulations across Europe and the issues of identification and security as critical for the DBE platform development.

More specifically SME software service providers, such as Nemein ${ }^{\mathrm{vi}}$ and Integratum ${ }^{\mathrm{vii}}$ in Finland, raised identification and security as the two most important issues of regulatory interest, while approaching them from a business-like perspective. 
The SMEs mostly emphasised that the architecture of the DBE platform must ensure the secure transfer of data, arguing that for SME software service providers a major concern is that identification is tightly related to serious security risks entailing the danger of data loss during data transfer in the DBE platform. In this regard, Nemein's argument is indicative:

Well, as the DBE [platform] identification environment is now, the platform gives no guarantee [of security]...if I want to find Nemein's open DSS system through the DBE platform and then a get a reference to the system, there is no guarantee that there is actually a system and then I could have some sensitive project data that is not meant for other than Nemein. Unless I get a guarantee that this is really, really a reference to Nemein system, I can't trust the system to transfer the data I want to.

Another concern for the SME software service providers in Finland was raised in respect to contractual issues. Since SME software service providers mostly deal with software management and clients having private data, they expressed a strong concern regarding the extent to which the existing DBE platform is in a position to ensure the confidentiality of data and consumer protection. This, in turn, raises the issue of contracts and agreements between contractors, since different terms and conditions with respect to consumer data may apply:

INTEGRATUM: Maybe contractual issues [within the DBE] are somehow [not clear]... since they are not clear to us...

Interviewer: What are your thoughts on that?

INTEGRATUM: From a business point of view...how to make business through the DBE is something that we have to develop somehow...it is not clear yet. There is a plan of course but how can we, as a software company, get business from the DBE?

Interviewer: So the business ... 
INTEGRATUM: ... what is the contractual basis for us and other companies that use services that we have implemented within the DBE. In that sense, contractual issues are important but we haven't solved them yet.

\section{SME Users}

A second category encountered relates to the SMEs perception on their role as DBE users. Those SMEs related their main concern - the workability of the DBE platform - to the impact their potential membership might have on the trust relationships between DBE partners and the commercial world. Particularly the lack of secure commercial interfaces for the use of the DBE platform formed the foreground for respective regulatory concerns.

The critical matter of the quality and level of completion of the technical features of the DBE was

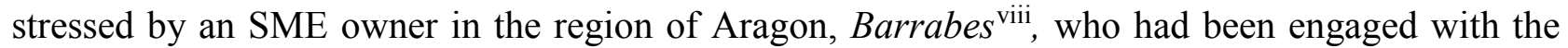
DBE since the project started while having very tight business links to leading companies such as Microsoft and Oracle. Hence, Barrabes have expressed their concerns about the testing of the various features of the platform and were frustrated by their poor understanding of how most of these features and tools work. This made them question the sustainability of the DBE platform in the long run as well:

Interviewer: What are your expectations from participating in the DBE?

BARRABES: I think it's a great idea. But once you come into the real world, it's going to be very difficult [to implement]...Because some things like those [software services] called semantic description and so on are very good...Well for someone like me it is very difficult cause I don't know how or where to start from. I think it's going to be even more difficult with the actual users cause they're going to say: "Eclipse can do this, but what am I going to do with this?"... Like Word or Excel or Access, right, I only use 10\% of their functions, and it's mainly because you know how it works. So I don't think the DBE case is going to be the 
same...the system [DBE] is not going to be fluent in terms of spreading its applications into the real world.

In addition, the future software-based contracts using online signatures was seen by some DBE users as encompassing potential issues of contractual obligations that should be supported by a knowledge base of regulatory guidelines. From this perspective, the SME Gabilos ${ }^{\text {ix }}$ in Aragon, who are not currently using e-signatures in their transactions with their costumers, have shown a strong interest in adopting e-signatures. However, they stressed the necessity for more implementation tools for use within the DBE, such as contracts and e-signature digital certification systems:

GABILOS: ...it is absolutely needed only if those contracts are available [electronically], DBE companies who have not contacted you before are likely to contact you...I think it will be very interesting!

Interviewer: At the moment, because there are no contracts online, there are no e-signatures online. If these things were in place, would this be positive for the SMEs, in terms of maintaining the DBE long-term sustainability?

GABILOS: Yes!

Business Analysts

Finally, for SMEs which aim to operate as DBE business analysts, their role was seen as intrinsically linked to the development of trust relationships with DBE partners and users, while evaluating the ecosystem on the basis of the provision of benefits and costs that have long-term incentives for the development of open source applications in the platform. Openscape ${ }^{\mathrm{x}}$ in the UK argued, in this respect: 
OPENSCAPE: We see that we are contributing. We haven't taken back anything yet... We've put in a lot more than we've taken out. We're going to be testing and giving feedback based on our commercial experience.

Interviewer: So in the short-term more costs than benefits?

OPENSCAPE: Yes, but in long term we see benefits because we'll have an idea that it's going to work and so we'll have a bit of a lead over other companies. We'll have a service, which if it works properly will be used by other people.

These concerns also relate to the commercial incentives for the development of open source middleware. Openscape, which has a solid open source base for their business model, had strong incentives for pushing middleware software releases over an open source model, pointing to implications for trust and sustainability in the system:

OPENSCAPE: ...you don't just push anything. If you want to receive stuff from SMEs you've got to put the right structure there and they have to decide what they want. There has to be a central authority; there always is in open source. The authority accepts contributions from companies. Things that are commercial tend to survive. With open source there is a big commercial element. People are not doing it out of the goodness of their heart...

\section{Implications for trust and regulation issues for SMEs in the EU}

From the above case-based discussion, it is possible to appreciate that there is enough evidence to infer a significant correlation between the taxonomy tools applied to the DBE and the regulatory issues that the SMEs perceive as relevant. The empirical findings reported in this section provide some indicative evidence of how the taxonomy can guide in a new way to structure knowledge in the field, as well as the implications for trust and regulation in the field. 
For instance, the SME Software Service Providers argued about the importance of trust in the platform, while underlining the possible risks that might arise for future trustful and responsible behaviour amongst DBE participants:

INTEGRATUM: ...yes that is true. There has to be some level of trust and, as a software company, of course we always care because technical issues have to be in good shape...and there must be trust for that. That is...I think that is the question...it can't be any problems in that area if someone wants to see the DBE in future success..."

Also, the SME users' concerns related to technical issues raise the issue of trust as a measure of confidence expressed in terms of security and reliability in the DBE. These actors argue about the limited commercial impact of the platform referring to trust concerns about safety and security risks within the DBE and among SME users. Barrabes, for instance, underlined how the shortage of trust and the subsequent security concerns have made them be reluctant about using Open Source, supporting the 'security' that proprietary software offers and challenging the business prospects of the DBE platform.

Nevertheless, an application of the taxonomy needs to highlight the dynamic and complex relationships between regulatory areas of interest and businesses in the EU. Therefore, flexible regulatory provisions must be in place, so that regulatory and business evolution can bring to the fore new requirements and tools, influencing and synchronising the taxonomy itself, as well as other business regulation frameworks in the EU. Tools of this type, such as a regulatory search engine, were designed by DBE computing science researchers. 


\section{$\underline{\text { CONCLUSION }}$}

This paper describes the components for a taxonomy of regulatory issues in digital business ecosystems. This taxonomy was devised through theoretical and applied work carried out in the EU-funded DBE project. In general, regulatory considerations are an important part of ensuring the realisation of the e-business ecosystem vision in the long run. The challenges currently faced by the SMEs in the regulatory domain are an important barrier that will need to be overcome in order to both encourage SMEs to take up e-business opportunities and establish trust relationships within the ecosystem as well as between its participants.

The particular importance of regulatory trust for e-business in digital business ecosystems was formalised into a taxonomy that is intended to address those issues through modelling and populating them. The taxonomy all together should be regarded as a dynamic knowledge base of regulatory issues that develops in a continuous, evolutionary way. It will also need to be expanded to a set of sector-specific and local implementation regulatory cases. Thus and on the grounds of the issues highlighted by the SMEs in the empirical testing of the taxonomy, the authors have identified the following three areas for further work:

Firstly, in the area of privacy and consumer protection, questions regarding the types of data that SMEs will deposit and exchange within the ecosystem environment and the respective regulatory controls to apply need to be further examined. This raises questions concerning the management of the databases and how it complies with regulatory requirements and commercial needs for protecting sensitive data in the DBE, as well as the means for determining data sharing between ecosystem members and with third parties. 
Secondly, in the domain of e-signatures and authentication, a number of questions regarding the level of security requirements which are applicable to the transactions carried out by the SMEs are still unanswered. Models for establishing the hierarchy of authentication relevant to selected sector and local implementation are needed. In addition, the requirements for generating traceable records and the ways this can affect the transactions in the environment are issues requiring further attention. This draws attention to issues related to invoicing system interoperability and traceability of invoice and payment information relevant for particular business areas/sectors where these issues arise. Thus, from a future perspective, it raises questions about how critical security requirements will be affected by differences in regulations between member states.

Finally, the area of cross-border online contracting within the e-business ecosystem vision raises issues regarding possible barriers to recognition of electronically concluded contracts in the selected implementation cases with possibly serious implications for the DBE contracts framework. This poses the question of how issues of jurisdiction could be of relevance to SMEs, entailing implications for participation. Relevant possible solutions, such as online dispute resolution schemes (ODR), available for the SMEs should be identified and the possibilities and mechanisms for including them directly in the DBE system to be considered.

These three areas of research were brought up in the interviews with SMEs as important for the identification of sector-specific and local-implementation regulatory issues in digital business ecosystems. At the same time, the SMEs stressed, overall, the significance of regulation for establishing trust relationships among participants and for ensuring long-term sustainability of the system as a whole. Nevertheless, the development of the taxonomy is an important step forward as a meta-model which enables it to accommodate specification and further evolution of the knowledge base. The evolutionary potential of the taxonomy must be taken seriously into account 
when discussing the taxonomy's utility for the digital business ecosystems, as dynamic relationships among the various regulatory areas of taxonomy is the key to possible future dynamic changes confirming the ephemeral character of the framework itself. Thus, the empirical insights obtained from interviewing SMEs can constitute the starting point for testing and enriching the taxonomy framework in the future, possibly through quantitative research.

Further research on digital business ecosystems is of particular significance, as it will enable the essential update and sustainability of the DBE goals in the long run. At the same time, in order for

the DBE vision to be fulfilled, governance issues and questions such as the interrelations of governance and management should be further addressed in accordance with regulatory areas and the evolving character of the taxonomy itself.

Since the DBE project completion, a follow up project funded by the EU, denominated "OPAALS (Open Philosophies and Autopoietic digitaL ecosystemS) Network of Excellence" has been able to continue the research path established by the DBE and extend the findings at the core of its research work outside the boundaries of Europe to India, Brazil and China.

\section{REFERENCES}

Berkey, J. (2002) Outline of International e-commerce regulatory issues. Intel/Unitar Campus of New Information and Communication Technologies and Diplomacy, New York, US.

Black, J. (2002). Critical Reflections on Regulation. London: Centre for Analysis of Risk and Regulation (CARR), London School of Economics and Political Science, pp.1-29.

Burn, J. (2000) Editorial, Journal of Global Information Technology Management 3(1): 3-7. 
Clarke, R. (2002a) Trust in the context of e-Business, Internet Law Bulletin 4(5): 56-59.

Clarke, R. (2002b) e-Consent: A Critical Element of Trust in e-Business, in 15th Bled Electronic Commerce Conference (Bled, Slovenia, 2002) [WWW document] http://www.anu.edu.au/people/Roger.Clarke/EC/eConsent.html (accessed 1st March 2009).

Dutton, W.H. and Shepherd, A. (2004) Confidence and Risk on the Internet. Foresight Cyber Trust \& Crime Prevention Project. Government Office for Science, Department of Innovation, University and Skills, London, UK.

Ebusinesslex (2005) The E-business Legal Portal [WWW document] http://www.ebusinesslex.net/front/ele_paesi_leggi.asp (accessed $7^{\text {th }}$ March 2007).

E-businessWatch (2004) The European e-Business Report: A portrait of e-business in 10 sectors of the EU economy. EU Publications, Edition 2004.

European Commission (2005) The activities of the European Union for small and medium-sized enterprises (SMEs) - SME Envoy Report, Brussels, Belgium [WWW document] http://europa.eu.int/comm/enterprise/entrepreneurship/sme_envoy/index.htm (accessed 1st March 2007).

Hornby, G., Goulding, P. and Poon, S. (2004) Perceptions of Export Barriers and Cultural Issues: The SME e-Commerce Experience, Journal of Electronic Commerce Research 3(4): 213-226.

Hornle, J. (1999) Electronic Commerce Legal Issues Platform II, London: IT Law Unit, CCLS, Queen Mary College, pp. 1-29.

Jarvenpaa, S. L. and Tractinsky, N. (1999) Consumer Trust in an Internet Store: A Cross-Cultural Validation, Journal of Computer Mediated Communication 5(2): 45-71.

Keen, P. G. W. (2000) Ensuring E-trust, Computerworld 34 (11), p. 46.

Mansell, R. and Collins, B. (2004) Cyber Trust and Crime Prevention: A Synthesis of the State-ofthe-Art Science Reviews. Foresight Cyber Trust \& Crime Prevention Project. Government Office for Science Department of Innovation, University and Skills, London, UK. 
Mahler, T. and Vraalsen, F. (2004) Preliminary Analysis on Legal Issues, Trustcom Research Consortium.

Mayer, R. C., Davis, J. H. and Schoorman, F. D. (1995) An integrative model of organizational trust, Academy of Management Review 20: 709-734.

Meents, S., Tan, Y-H. and Verhagen, (2003) Distinguishing different types of trust online B2B marketplaces, in the Tenth Research Symposium on Emerging Electronic Markets 2003 (University of Bremen, Germany, 2003); Bremen: University of Bremen. 53-65.

Nachira, F. (2002) Towards a Network of Digital Business Ecosystems Fostering the Local Development. Discussion Paper [WWW document] http://www.digital-ecosystems.org/ (accessed $7^{\text {th }}$ March 2007).

Pavlou, P. A. (2002) Institution-Based Trust in Interorganizational Exchange Relationships: The Role of Online B2B Marketplaces on Trust Formation, The Journal of Strategic Information Systems 11(3-4): 215-243.

Rosenbaum, H. (2004) The importance of trust in the digital networked economy, in workshop "Creating partnership online" Concept and Tools (Darmstadt, Germany, 2004).

Ruppel, C., Underwood-Queen, L. and Harrington, S. J. (2003) E-commerce: The Roles of Trust, Security, and Type of Ecommerce involvement, e-Service 2(2): 25-45.

Shankar, V., Urban, G.L. and Sultan, F. (2002) Online trust: a stakeholder perspective, concepts, implications, and future directions, Journal of Strategic Information Systems 11: 325-344.

Schoubroeck Van, C., Cousy, et al. (2001a) Virtual Enterprise Legal Issue Taxonomy. Leuven, Belgium, K.U Leuven University - ALIVE Project. [WWW document] http://www.viveig.net/projects/alive/Documents/Virtual_Enterprise_Legal_Issue_Taxonomy.zi p (accessed 15th January 2007). 
Schoubroeck Van, C., Cousy, H. et al. (2001b) A Legal Taxonomy of Virtual Enterprises. Leuven, Belgium, K.U. Leuven University - ALIVE Project. [WWW document] http://www.viveig.net/projects/alive/proc/Leuven-paperICE01.zip (accessed 25th January 2007).

Shelbourn, M., Hassan, T. et al. (2003). Identification of the potential Legal and Contractual gaps and problems within the cluster projects. Loughborough: Loughborough University - ICCI.

Spindler, G., Carter, C. et al. (2004). State of the Art of Research on Legal Issues Related to the Information Society Technologies. Dublin: Legal IST.

Sultan, F., Urban, G. et al (2002) Determinants and Role of Trust in E-business: A Large Scale Empirical Study. MIT Sloan Working Paper Series [WWW document] http://ecommerce.mit.edu/cgi-bin/viewpaper?id=231 (accessed $5^{\text {th }}$ March 2007).

Swan, M. and Rosenbaum, H. (2004) The social construction of trust in e-business: An empirical investigation. Americas Conference on Information Systems [WWW document] http://aisel.isworld.org/pdf.asp?Vpath=AMCIS/2004\&PDFpath=SIGEBZ01-1766.pdf (accessed $5^{\text {th }}$ March 2007).

Yovovich, B. G. (1996) Trust Among Partners Foundation of Success, Advertising Age's Business Marketing 81(6): 12-15. 


\section{ANNEX}

\section{Figure IV: Survey of Regulatory Issues}

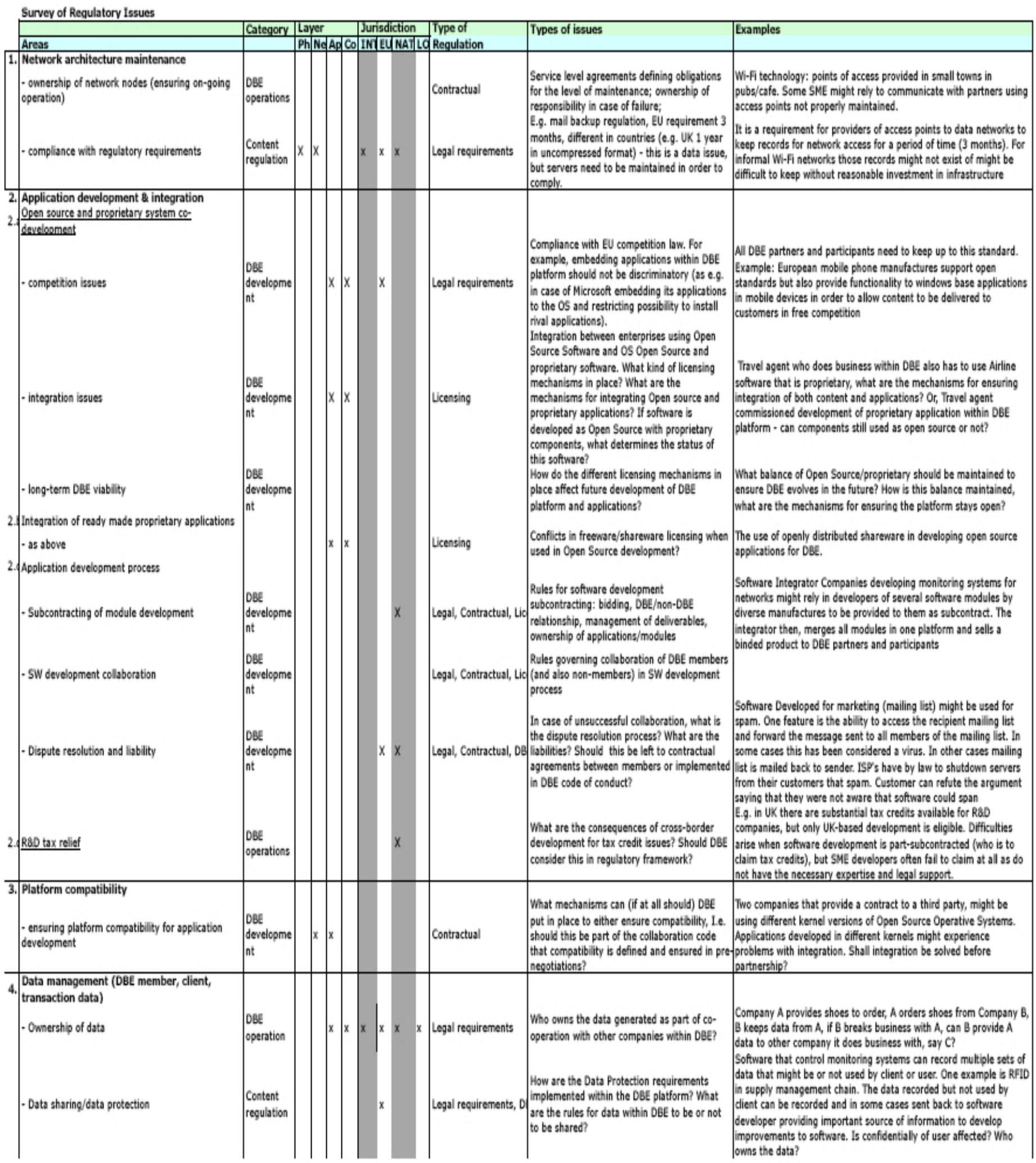




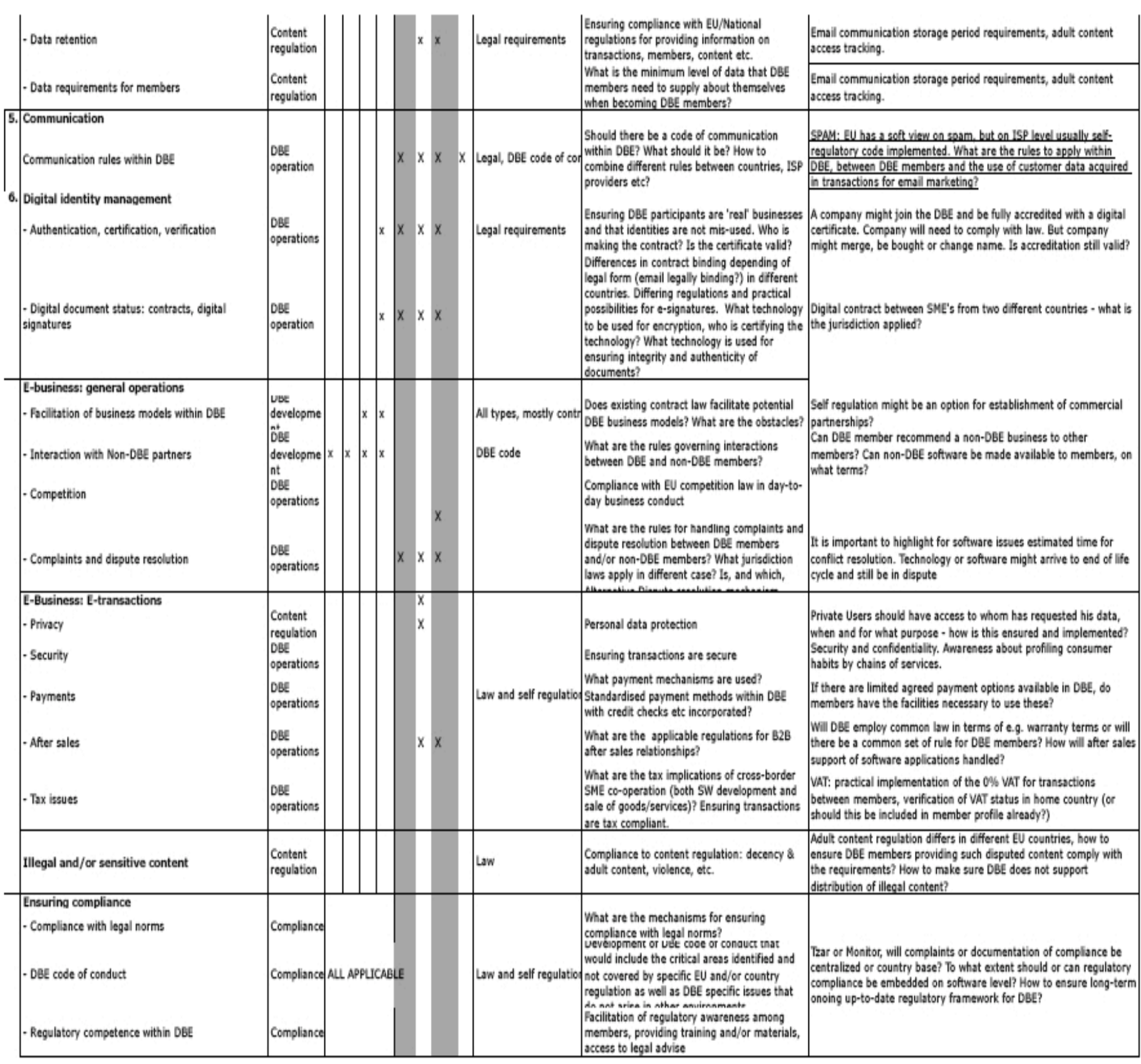

Framework Layer Ph=physical, Ne=network/transport, Ap=applications $C_{0}=$ content INT=International, EU, LOC=local, NAT=national 


\section{Background on Interviewed SME Drivers}

\section{West Midlands: Pollard, Openscape, and Redenet}

The three interviewees in the West Midlands were selected on the basis of their long engagement with the DBE. At least two of them, Pollard and Openscape, were generally concerned about the present and future of the DBE. Moreover, the interviewees in the West Midlands represent a spectrum of business domains, covering the areas of online accounting, e-commerce and web design and consultancy. Hence, they give to the task the opportunity to identify regulatory issues of concern at various levels of engagement and in different business domains, allowing the articulation of arguments regarding the sector-specific dimension of the aspired Knowledge Base of Regulatory Issues.

\section{Finland: Nemein and Integratum}

The Drivers in Finland constitute a rather different usage scenario from the one in the West Midlands. More specifically, both Drivers in Finland belong to the same business sector, developing activities in Java-based enterprise information systems integration, while they constitute active contributors towards the technical implementation of the DBE platform. More specifically, they both have undertaken the following integration projects within the DBE:

2.a Nemein work and position within the DBE:

- Integrating the Open PSA project management system into the DBE framework.

- Enabling companies to share project information and expense reports automatically with their partners and contractors.

2.b Integratum work and position within the DBE:

- Integrating CentraView OSS CRM system to DBE Framework and implement a service that allows users to import and export CentraView 
- Contact data.

- Importing and exporting contact data using XML files.

Hence, the Drivers in Finland allow the task to proceed to a comparative analysis of the initial identification of sector-specific and local implementation regulatory issues, reflecting on the generic level taxonomy.

\section{Aragon: Barrabes and Gabilos}

The Spanish Drivers constitute centralised business networks, where ITA (Regional Catalyst) is at the epicentre controlling them. In Aragon, all engaged Drivers3 belong to one sector, the tourist sector, and carry out diverse programs that cover the management of the SMEs and, in particular, the management of rural tourism, the management of hotels, accounting, turnover, payrolls, boards of repayment, accounting general plan, and so on.

Although both interviewed Drivers belong to the same business sector, their business activities vary, with Barrabes being a regional influencer and a famous4 example of a successful IT SME in the area developing activities in e-commerce and consultancy in the tourist sector, while Gabilos develop management software for other SMEs in the same sector. More specifically:

\section{3.a Barrabes:}

- E-commerce industry.

- Consultancy, dedicated to help Spanish companies develop their businesses around the world.

- Communication link between IT developers and tourism businesses.

\section{3.b Gabilos:}

- Software programs that cover the management of the SMEs, such as management of rural tourism, management of hotels, accounting, turnover, payrolls, boards of repayment, accounting general plan, etc. 
Hence, the interviews in Aragon allow the task to approach regulatory issues in accordance with the views of Drivers attempting to boost business within the DBE platform, offering thus a different perspective of sector-specific and local implementation issues while reflecting, validating and/or updating the generic level taxonomy with the issues 


\section{Interview Topic Guide}

\section{A. Background questions: company profile and current business situation}

- Core business activities

- History of activities in a digital collaborative environment

- Current opportunities and challenges that the company is facing

- Business collaboration across Europe: level, types of collaborative activities and regions where collaboration takes place

\section{B. Regulatory concerns and legal issues raised by theory}

- Privacy \& Consumer protection at the level of Tryst types X, Y \& Z, and across varying Operational Perspectives (within diverse DBE relationships, for different DBE actors and with different software life cycles)

- E-signatures \& authentication at the level of Tryst types X, Y \& Z, and across varying Operational Perspectives (within diverse DBE relationships, for different DBE actors and with different software life cycles)

- Jurisdiction \& consumer protection at the level of Tryst types X, Y \& Z, and across varying Operational Perspectives (within diverse DBE relationships, for different DBE actors and with different software life cycles)

\section{Regulatory concerns and legal issues raised by current business practices}

Open discussion where other legal issues might be raised by the interviewees, such as business competition, conduct and liability rules, intellectual property vs. freedom of knowledge, confidentiality/sharing of information, copyright, exploitation rights, digital right management, etc. 


\section{Underlying factors influencing Drivers' concerns}

- What are the main factors affecting the company in how it deals with the above regulatory issues?

- What is the role that the particular business sector plays in this respect?

- Whether and to what extent the local factor influences accordingly

\section{E. Challenges for the DBE}

- How do the interviewees anticipate that the DBE might deal with the above regulatory concerns?

- Proposals, suggestions and further remarks from the interviewees regarding the regulatory provisions of the DBE 


\section{FIGURE AND TABLE LEGENDS}

Table I: Trust Categories

Table II: DBE Operational Perspectives

Figure I: Building blocks of regulatory issues and three layers of examination

Figure II: A three-dimensional representation of the taxonomy

Figure III: Criteria for case selection 


\section{FIGURES AND TABLES}

\section{First author's name: Panayiota Tsatsou}

\section{Table I: Trust Categories}

\begin{tabular}{|l|l|}
\hline Trust Type & \multicolumn{1}{c|}{ Description } \\
\hline $\mathrm{X}$ & $\begin{array}{l}\text { This refers to trust held by joining companies towards the DBE. From a regulatory } \\
\text { perspective, the expectation is that technical architecture and basic services incorporate } \\
\text { the existing e-business regulations, and provide facilities for carrying out transactions in a } \\
\text { way that will ensure compliance with established laws and norms. }\end{array}$ \\
\hline $\mathrm{Y}$ & $\begin{array}{l}\text { This type of trust refers to the expectation from established DBE participants towards } \\
\text { joining companies. In order to establish good trust relationships, companies are expected } \\
\text { to comply with existing laws and norms, and to avoid creating unnecessary risks for their } \\
\text { DBE counterparts. }\end{array}$ \\
\hline $\mathrm{Z}$ & $\begin{array}{l}\text { Trust type Z refers to the trust relationships between DBE participants themselves. This } \\
\text { type of trust is supported by confidence in the ability of norms and laws to govern the } \\
\text { interactions resulting in part from the self-organisation and evolution of the DBE } \\
\text { environment. }\end{array}$ \\
\hline
\end{tabular}




\section{First author's name: Panayiota Tsatsou}

\section{Table II: DBE Operational Perspectives}

\begin{tabular}{|c|c|c|}
\hline Perspective & & Description \\
\hline \multirow[t]{2}{*}{$\begin{array}{l}\text { DBE } \\
\text { Relationships } \\
(*)\end{array}$} & Internal & $\begin{array}{l}\text { - Arise in the ecosystem environment and are specific to its setting (e.g. issues related } \\
\text { to the legal identity and applicable rules within the ecosystem, issues arising from } \\
\text { governance arrangements, legal challenges associated with the envisioned self- } \\
\text { organising processes in software creation); or } \\
\text { Issues are directly linked to ecosystem participants and their activities its } \\
\text { environment (e.g. issues related to transactions carried out within the digital business } \\
\text { ecosystem, copyright questions in regard to the integrated software, security and } \\
\text { data exchange, identity of ecosystem members). }\end{array}$ \\
\hline & External & $\begin{array}{l}\text { Those that are not in the power of the ecosystem members or governors }- \text { i.e. the } \\
\text { external regulations applicable to e-business activities, such as tax rules, consumer and } \\
\text { data protection regulations, contract and competition law provisions and so on. While the } \\
\text { DBE environment has to facilitate compliance with the rules, DBE actors themselves } \\
\text { cannot influence the existence of these provisions. }\end{array}$ \\
\hline \multirow[t]{3}{*}{$\begin{array}{l}\text { DBE } \\
\text { Actors }\end{array}$} & $\begin{array}{l}\text { SME } \\
\text { Service } \\
\text { Providers }\end{array}$ & $\begin{array}{l}\text { Provide digital (software component) services that use the DBE as an infrastructure } \\
\text { platform. SME service providers are the party responsible for the technical integration of } \\
\text { their services with the execution environment and the (technical) description of their } \\
\text { digital services on designer tools. }\end{array}$ \\
\hline & $\begin{array}{l}\text { SME } \\
\text { Users }\end{array}$ & $\begin{array}{l}\text { Use DBE services for their own business needs in a "self-consumption" way or in order } \\
\text { to undertake transactions with other users of the same or a compatible service. }\end{array}$ \\
\hline & $\begin{array}{l}\text { Business } \\
\text { Analyst }\end{array}$ & $\begin{array}{l}\text { Have a bridging function between both sides. They help users to get connected and } \\
\text { establish their DBE profiles. They also help service providers to integrate into service } \\
\text { chains and make services compatible. In that sense they perform manually what would } \\
\text { be the task of the evolutionary environment. }\end{array}$ \\
\hline \multirow[t]{2}{*}{$\begin{array}{l}\text { DBE } \\
\text { Software } \\
\text { Lifecycles } \\
(* *)\end{array}$} & $\mathrm{FS} / \mathrm{OS}$ & $\begin{array}{l}\text { It is a way of developing software by consensus, with open access for developers to } \\
\text { source code. Communication takes place through the Internet and collaboration is } \\
\text { facilitated by the use of Internet based collaboration tools (such as CVS). There is no } \\
\text { proprietary ownership of the source code and the code is licensed to prevent such } \\
\text { ownership. }\end{array}$ \\
\hline & Proprietary & $\begin{array}{l}\text { In order companies to increase speed, they can overlap parallel development-releases are } \\
\text { developed in parallel or staged onto the market such that design, development and } \\
\text { quality assurance occur simultaneously. }\end{array}$ \\
\hline
\end{tabular}

(*) In some cases, regulatory issues will be classified as both external and internal. For instance, drawing on an example from the ALIVE project (Schoubroeck et al 2001a), the use of digital signatures by the ecosystem members as part of authentication procedures is affected by the certification regulations and externally existing certification arrangements.

(**) The two models summarised above are based on the common software lifecycle classification; however, other software development methodologies may prove significant in digital business ecosystem contexts (such as Unified Process or Agile Methods). 
First author's name: Panayiota Tsatsou

Figure I: Building blocks of regulatory issues and three layers of examination

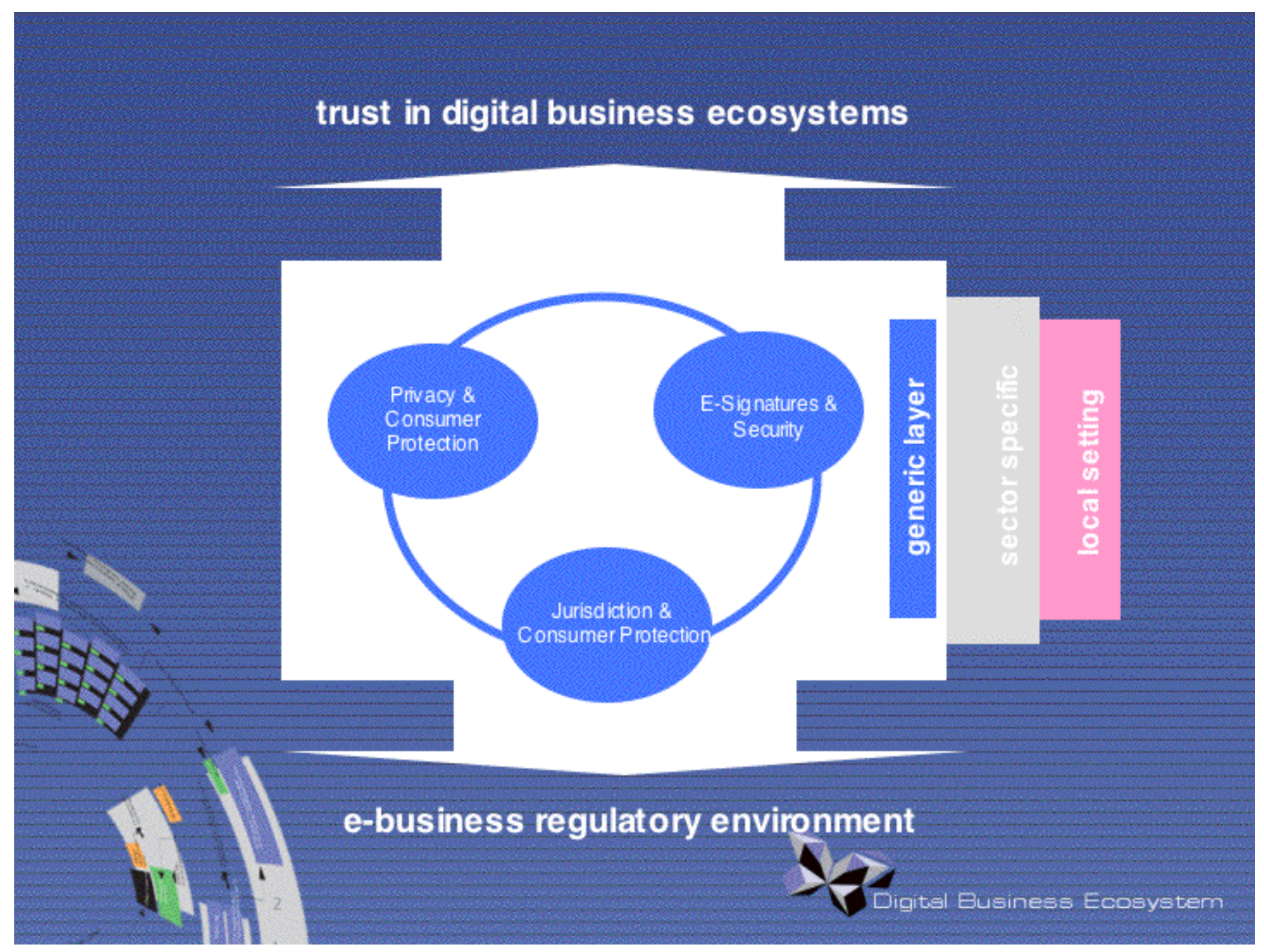


First author's name: Panayiota Tsatsou

Figure II: A three-dimensional representation of the taxonomy $\left(^{*}\right)$

Taxonomy: Knowledge Base of Regulatory issues

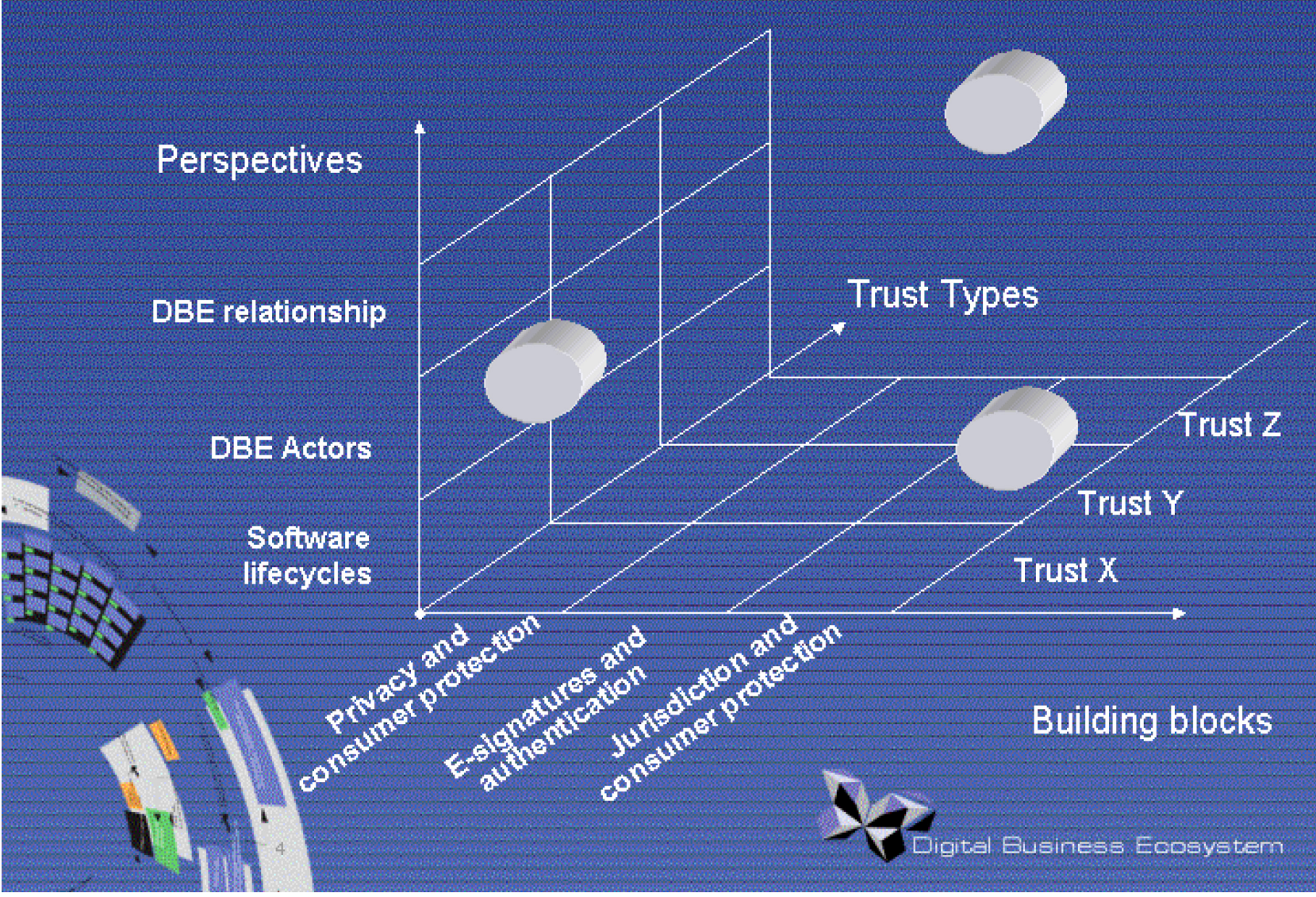

(*) The grey cylinders on the diagram are used to illustrated the complexity on the taxonomy issues identified in relation to the different types of trust as described in pages 16 and 17 of this document. 
First author's name: Panayiota Tsatsou

Figure III: Criteria for case selection

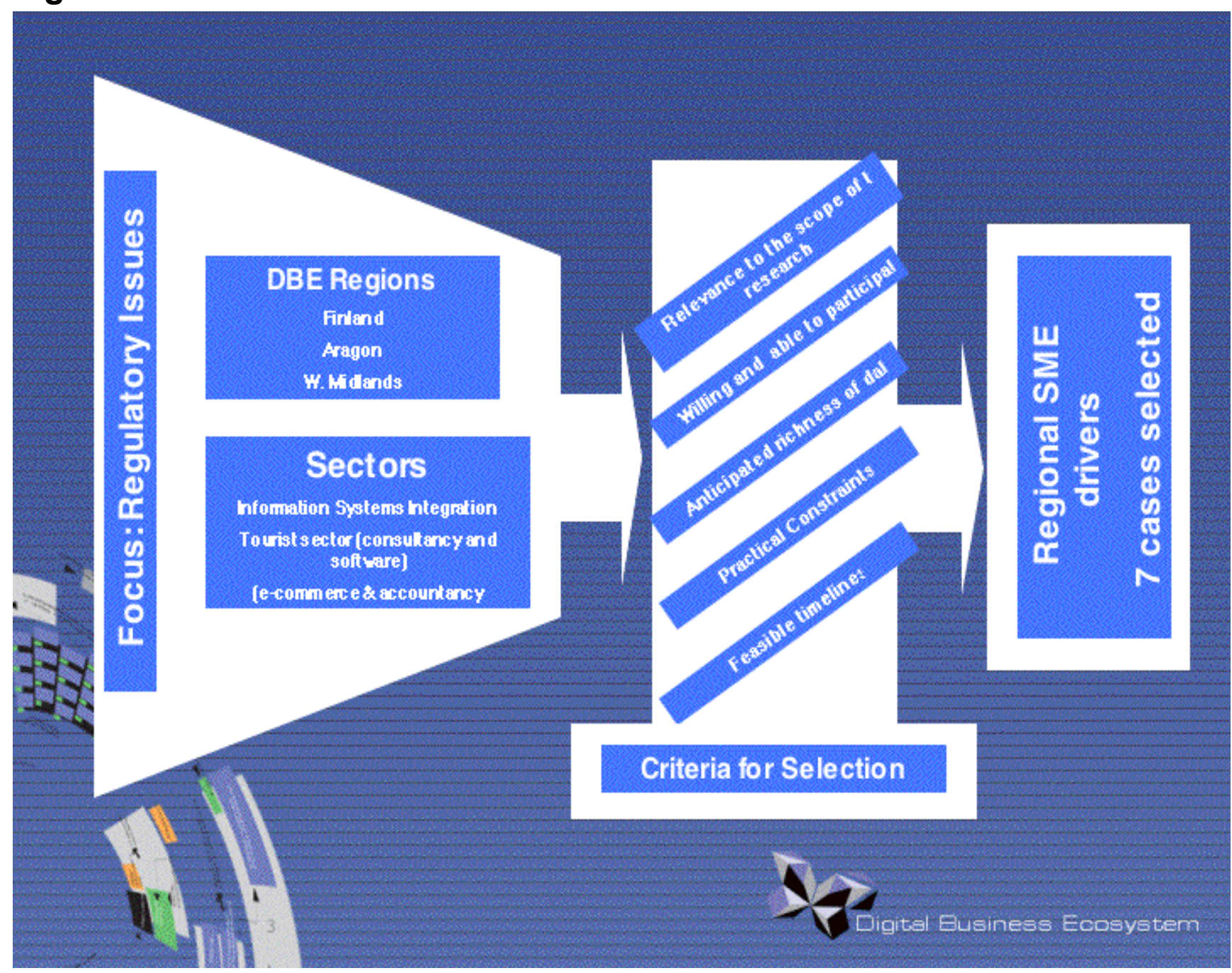




\section{NOTES}

${ }^{i}$ The DBE Project was a 3-year, $€ 14$ million pan-European project, involving 120 researchers and specialists from 20 organisations, supported by the European Commission's 6th Framework Programme for research and development in information society technologies. See the project website: http://www.digital-ecosystem.org/.

${ }^{\text {ii }} \mathrm{A}$ knowledge base of regulatory issues refers to the baseline understanding of the policy and regulatory domain within which the DBE is being conceptualized, created, and implemented. This foundation is intended to provide fundamental perspectives on a range of issues that have been identified in the literature as essential factors for establishing trust relationships in e-business settings, and specifically for small and medium-sized enterprises (SMEs) in the EU.

iii The notion of 'knowledge' is proposed instead of that of 'information', as the aim is not to create an online database or information repository of regulatory issues of importance for SMEs participating in the DBE. Rather, the aim is to reflect on and represent matters of concern to SMEs through providing a regulatory framework which will be a 'living', evolving and adjustable object over time. Hence, we aim at problematising issues of regulation by providing a reflective framework of them.

iv We draw the working definition of taxonomy from an approach adopted by the ALIVE project on legal issues for virtual organisations (IST 2000-25459): '[A] taxonomy should be regarded as a quest, setting out the boundaries of the main research subject and providing a preliminary framework of guidelines for an in-depth analysis of the [regulatory] issues related to the [project]. The taxonomy... initiates further research by... pointing out the most problematic legal questions, clarifying and illustrating the significance of certain [regulatory] issues. The taxonomy does not present [regulatory or legal] solutions to these issues' (Schoubroeck et al 2001a).

${ }^{v}$ For the full interview guide, see Annex 3.

${ }^{v i}$ Nemein deals with Java-based enterprise information systems integration and it is located in Finland. Company website: http://www.nemein.com.

vii Integratum deals with Java-based enterprise information systems integration and it is located in Finland. Company website: http:// www.integratum.fi/.

viii Barrabes deals with consultancy and e-commerce in the tourist sector and it is located in the region of Aragon in Spain. Company website: http://www.barrabes.biz/.

${ }^{\text {ix }}$ Gabilos deals with management software in the tourist sector and it is located in the region of Aragon in Spain. Company website: http://www.gabilos.com.

${ }^{x}$ Openscape deals with web design and consultancy and it is located in West Midlands, in the UK. Company website: http://www.Openscape.co.uk. 